\title{
Profil Kondisi Fisik Atlet Futsal Saba Fast dalam Menghadapi Liga Futsal Kabupaten Bandung Barat
}

\author{
Profile of Physical Conditions Of Futsal Saba Fast Atlhletes in Facing the \\ West Bandung Regency Futsal League
}

\author{
Ricky Ferrari Valentino, Ariyanto Bayu Saputro \\ STKIP Pasundan, Cimahi, Jawa Barat, Indonesia \\ rickyalel@yahoo.co.id
}

\begin{abstract}
Abstrak
Penelitian ini bertujuan ingin mengetahui seberapa baik profil kondisi fisik pada atlet futsal Saba Fast di Kabupaten Bandung Barat. Metode penelitian yang digunakan adalah metode deskriptif melalui pendekatan survey. Populasi yang digunakan dalam penelitian ini adalah seluruh jumlah atlet futsal Saba Fast di Kabupaten Bandung Barat sebanyak 20. Sedangkan sampel dalam penelitian ini adalah atlet futsal Saba Fast di Kabupaten Bandung Barat sebanyak 20. Teknik pengambilan sampel menggunakan teknik total sampling, artinya sampel yang diambil berdasarkan jumlah keseluruhan populasinya yaitu seluruh jumlah atlet futsal Saba Fast di Kabupaten Bandung Barat sebanyak 20. Dengan perolehan rata-rata persentase dari keseluruhan komponen kondisi fisik yaitu pemain futsal Saba Fast di Kabupaten Bandung Barat. Hasil rata-rata tes kekuatan otot (push up) yaitu 42.65 berkategori sempurna, tes kekuatan otot (sit up) yaitu 44.60 berkategori sempurna, kelincahan perolehan rata-rata tes 17.60 detik dengan kategori cukup, hasil rata-rata tes kecepatan perolehan rata-rata tes 3.86 detik dengan kategori baik, kekuatan otot tungkai yaitu 1.06 meter berkategori sempurna, tes daya tahan perolehan rata-rata tes 16.2 dengan kategori cukup.
\end{abstract}

Kata Kunci: Profil Kondisi Fisik, Futsal

\begin{abstract}
This study aims to find out how well the profile of physical conditions in Saba Fast futsal athletes in West Bandung Regency. The research method used is descriptive method through a survey approach. The population used in this study was 20. The number of futsal Saba Fast athletes in West Bandung Regency was 20. While the samples in this study were 20 futsal Saba Fast athletes in West Bandung Regency, the sampling technique used was total sampling technique, meaning the samples were taken based on the total number of population is 20. The number of futsal Saba Fast athletes in West Bandung Regency is 20. With the average percentage of the overall components of the physical condition, Saba Fast futsal players in West Bandung Regency. The average muscle strength test (push up), which is 42.65 in perfect category, muscle strength test (sit up), which is 44.60 in perfect category, agility in the average test score of 17.60 seconds with sufficient category, the average yield of average speed test 3.86 seconds test with good category, leg muscle strength which is 1.06 meters in perfect category, endurance test obtained 16.2 test average with enough category.
\end{abstract}

Keywords: Physical Condition Profile, Futsal 


\section{PENDAHULUAN}

Adanya event Liga Futsal Nasional tentunya akan menjadi sarana untuk mengasah kemampuan para pemain. Tim Futsal Saba Fast di Kabupaten Bandung Barat ada berbagai permasalahan, salah satunya permasalahan kondisi fisik yang belum maksimal mungkin. Seluruh pemain futsal Saba Fast di Kabupaten Bandung Barat belum memiliki kondisi fisik yang maksimal, hal ini dimungkinkan karena kemampuan seorang pelatih belum memantau secara benar tentang kondisi fisik pemainnya dan belum ada data-data kondisi fisik pemain-pemain tersebut.

Kondisi fisik merupakan prasyarat yang harus dimiliki oleh seorang atlet di dalam meningkatkan dan mengembangkan prestasi olahraga yang optimal, sehingga segenap kondisi fisiknya harus ditingkatkan sesuai dengan ciri, karakteristik dan kebutuhan masing -masing cabang olahraga (Rudiyanto, 2012). Penguasaan teknik dan taktik, kondisi fisik yang prima dan mental dalam permainan futsal sangat menentukan prestasi. Dalam permainan futsal kemampuan daya tahan pemain yang baik merupakan dasar agar dapat bersaing dalam meraih prestasi yang maksimal, seperti yang diungkapkan oleh pelatih Timnas Futsal Putri Indonesia Hendra Nazir, "Bahwa rendahnya kemampuan fisik pemain itu bisa diketahui dari tingkat VO2Max atau kadar oksigen dalam darah". Menurut Adi Nurhadi sebagai pelatih fisik Timnas Futsal Putri Indonesia, target tingkat VO2Max untuk pemain Timnas Putri adalah sebesar 48 sampai 50 ml/kg BB/menit. Maka kondisi fisik merupakan hal yang fundamental bagi pemain dalam pertandingan, karena tanpa dukungan kondisi fisik yang prima akan sulit meraih prestasi yang maksimal (Surya, 2013).

Melalui kondisi fisik yang terprogram, kondisi fisik pemain yang kurang baik akan meningkat, seperti daya tahan (aerobic) lebih besar, kecepatan semakin meningkat, kekuatan semakin besar. Namun para pemain Saba Fast di Kabupaten Bandung Barat belum ada data yang spesifik mengenai adanya peningkatan maupun penurunan kondisi fisik. Serta dalam permainan berlangsung terjadi pergantian pemain dalam selang waktu 4-6 menit dikarenakan daya tahan pemain yang kurang maksimal. Jika dipaksa untuk bermain kesalahan akan muncul baik dalam posisi bertahan maupun menyerang. Untuk mendapatkan kondisi fisik yang maksimal terdapat 7 macam komponen yang perlu dilatih dan dikembangkan yaitu diantaranya daya tahan jantungpernafasan peredaran darah, kelentukan persendian, kekuatan, daya tahan otot, kecepatan, agilitas, dan power. Dengan peningkatan kondisi fisik tersebut diharapkan dalam permainan futsal seorang pemain mampu memiliki kestabilan yang baik (Setiawan, et al, 2005).

Melihat karakteristik permainan futsal, tidak semua komponen fisik harus dimiliki secara baik, namun ada komponen yang lebih dominan yang dimiliki pemain futsal adalah daya tahan (endurance), kekuatan (strength), kecepatan (speed), tanpa meninggalkan komponen yang lain. 
Permainan futsal yang cepat dengan durasi 2 x 20 menit dan lapangan yang relative dituntut setiap pemain memiliki daya tahan stamina, kecepatan, kelincahan, dan kekuatan yang baik (Lhaksana, 2011). Hal ini di karenakan dalam permainan futsal membutuhkan kecepatan dan kelincahan dalam bergerak, berlari, mengambil keputusan, mengantisipasi perubahan, membaca situasi permainan, mengubah pergerakan, defence, attacking, men-drible bola, menghalau bola, dan melakukan kombinasi perubahan (Almahdi, 2008). Dengan kestabilan komponen dominan kondisi fisik dalam futsal pemain akan bertahan lebih lama dengan baik selama permainan berlangsung selama 2 x 20 menit.

Pada kenyataanya dari pengamatan pada saat latihan dan pertandingan, sebagian besar pemain memiliki kemampuan baik dalam posisi menyerang (attacking), namun dengan tenaga yang menurun membuat kelemahan setiap pemain terlihat seperti salah satu pemain pivot yang memiliki tendangan keras namun kecepatan berlari dalam transisi menyerang (attacking) ke bertahan (defence) maupun sebaliknya sering terjadi keterlambatan. Pemain lainnya sebagai pemain flank juga memiliki kemampuan shooting yang keras dan memiliki kelincahan namun juga sering terjadi keterlambatan dalam transisi ke defence. Pemain flank yang lain yang memiliki kelincahan dan kecepatan namun untuk shooting ke arah gawang lawan masih mudah dihalau penjaga gawang.

Dari pengamatan tersebut dibutuhkan peningkatan tiap aspek komponennya terutama daya tahan pemain. Peningkatan daya tahan dalam bermain dapat terjadi dengan latihan kondisi fisik. Melalui latihan kondisi fisik yang teratur pada setiap komponennya kemampuan kondisi fisik dapat meningkat. Untuk menentukan program latihan dibutuhkan data spesifik awal mengenai kondisi pemain.

Saba Fast di Kabupaten Bandung Barat yang merupakan klub baru belum memiliki data spesifik awal mengenai kondisi fisik para pemainnya. Oleh karena itu dibutuhkan tes awal yang dapat dijadikan acuan dan daya kontrol pelatih dalam membuat program latihan. Dengan adanya persiapan dan pengetahuan pelatih akan kondisi fisik pemain, prestasi yang optimal selama mengikuti pertandingan akan terwujud. Selain itu harapan pelaksanaan tes ini pelatih dapat mengetahui kondisi fisik pemain, karena penelitian ini menyajikan profil data kondisi fisik pemain Saba Fast di Kabupaten Bandung Barat tahun 2018. Hasil penelitian ini dapat dijadikan penelitian ini dapat dijadikan acuan dalam merangcang program latihan kedepannya dan pantauan ada tidaknya peningkatan kondisi fisik setiap pemain. Tidak jarang banyak klub yang mengabaikan kondisi fisik pemainnya, karena beranggapan dengan latihan-latihan fisik sudah cukup tanpa perlu melakukan tes fisik.

Berkaitan dengan penjelasan di atas, bahwa penting untuk mengetahui kondisi fisik seorang pemain karena kondisi fisik merupakan hal yang fundamental bagi pemain. Melalui penelitian tes 
kondisi fisik diharapkan dapat mengetahui kondisi fisik pemain Saba Fast di Kabupaten Bandung Barat tahun 2018 sehingga pemain dan pelatih mampu bekerja sama untuk meningkatkan kondisi fisik pemain dalam bermain futsal dengan lebih maksimal.

\section{METODE PENELITIAN}

Adapun jenis penelitian deskriptif yang penulis gunakan dalam penelitian ini adalah pendekatan survei. Bahwa metode survey digunakan untuk mendapatkan data dari tempat tertentu yang alamiah (bukan buatan), tetapi peneliti melakukan perlakuan dalam pengumpulan data, misalnya dengan mengedarkan kuesioner, test, wawancara terstruktur dan sebagainya, dimana perlakuan tidak seperti dalam eksperimen (Sugiyono, 2014).

Populasi yang digunakan dalam penelitian ini adalah seluruh jumlah atlet futsal Saba Fast di Kabupaten Bandung Barat sebanyak 20 orang. Setelah populasi ditentukan maka kita menentukan sampel penelitian. Sampel adalah sebagian dari individu yang menjadi obyek dalam penelitian ini (Arikunto, 2012). Sampel sebagian atau wakil dari populasi yang akan diteliti dan dianggap mewakili seluruh populasi (Notoatmodjo, 2012).

Sedangkan yang dijadikan sampel dalam penelitian ini adalah atlet futsal Saba Fast di Kabupaten Bandung Barat sebanyak 20 atlet. Teknik pengambilan sampel menggunakan teknik total sampling. Total sampling merupakan teknik penentuan sampel bila semua anggota populasi digunakan sebagai sampel (Sugiyono, 2014).

Instrumen penelitian adalah alat atau fasilitas yang digunakan oleh peneliti dalam mengumpulkan data agar pekerjaannya lebih mudah dan hasilnya akan lebih baik, dalam arti lebih cermat, lengkap dan sistematis sehingga mudah diolah (Arikunto, 2012). Metode yang digunakan dalam penelitian ini adalah metode survei dengan teknik tes dan pengukuran. Melalui tes dan pengukuran peneliti akan memperoleh data yang objektif. Dalam penelitian ini, instrumen yang digunakan untuk pengambilan data terdiri dari 6 (enam) item tes, yaitu :

\section{A. Kekuatan Otot Lengan dan Bahu}

Instrumen yang digunakan untuk melakukan tes kekuatan otot, peneliti menggunakan tes push up yaitu untuk mengukur komponen daya tahan kekuatan otot lengan dan bahu.

\section{B. Kekuatan Otot Perut}

Instrumen yang digunakan untuk melakukan tes kekuatan otot, peneliti menggunakan tes sit up yaitu untuk mengukur komponen daya tahan kekuatan otot perut.

C. Kecepatan

Instrumen yang digunakan untuk meneliti tes kecepatan, peneliti menggunakan tes lari sprint 20 meter untuk mengukur kecepatan 


\section{Kelincahan}

Instrumen yang digunakan untuk meneliti tes kelincahan, peneliti menggunakan tes Illinois agility run untuk mengukur kelincahan dan koordinasi

E. Power Tungkai

Instrumen yang digunakan untuk meneliti tes power tungkai, peneliti menggunakan tes standing long jump untuk mengukur komponen power otot tungkai

F. Daya Tahan

Instrumen yang digunakan untuk meneliti tes daya tahan, peneliti menggunakan tes yoyo intermittent level 2 untuk mengukur daya tahan jantung dan paru-paru.

\section{HASIL DAN PEMBAHASAN}

\section{Hasil}

Hasil penelitian menunjukan bahwa secara keseluruhan kondisi fisik Atlet futsal Saba Fast di Kabupaten Bandung Barat tergolong dalam kategori baik. Hal tersebut ditunjukan dari beberapa tes fisik yang dilakukan. Tabel 1 memperlihatkan kondisi fisik berkategori baik yaitu dengan nilai konversi sebesar 7,3.

Tabel 1. Perolehan Rata-Rata Tes Fisik, Kategori, Konversi Nilai

\begin{tabular}{|l|c|c|c|}
\hline Komponen Fisik & Rata-rata & Kategori & Konversi Nilai \\
\hline Kekuatan otot & 42.65 & Sempurna & 10 \\
\hline Kekuatan otot & 44.60 & Sempurna & 10 \\
\hline Kelincahan & 17.60 & Cukup & 4 \\
& Detik & Baik & 6 \\
\hline Kecepatan & 3.86 detik & Sempurna & 10 \\
\hline Power tungkai & 1.06 & Cukup & 4 \\
\hline Daya tahan & 16.2 & & 7,3 \\
\hline \multicolumn{2}{|c|}{ Rata-rata } & & \multicolumn{2}{c|}{} \\
\hline
\end{tabular}

Dilihat dari tabel diatas terlihat komponen kecepatan, kekuatan otot memperoleh kategori sempurna, oleh karena itu dengan waktu dan pola pelatihna yang baik diharapkan akan tetap stabil dan tidak menunjukan penurunan pada ketiga komponen tersebut. Pada komponen fisik kekuatan otot memperoleh hasil dengan kategori baik, namun akan lebih baik jika ditingkatkan kembali sehingga akan lebih menunjang pada penampilan saat bermain dalam turnamen. Sedangkan pada komponen fisik kekuatan otot tungkai dan daya tahan aerobic memperoleh hasil dengan kategori cukup, oleh karena itu perlu ditingkatkan sehingga tujuan latihan fisik akan tercapai semaksimal mungkin. Hasil rata-rata tes kekuatan otot (push up) yaitu 42.65 berkategori sempurna, tes kekuatan 
otot (sit up) yaitu 44.60 berkategori sempurna, kelincahan perolehan rata-rata tes 17.60 detik dengan kategori cukup, hasil rata-rata tes kecepatan perolehan rata-rata tes 3.86 detik dengan kategori baik, kekuatan otot tungkai yaitu 1.06 meter berkategori sempurna, tes daya tahan perolehan rata-rata tes 16.2 dengan kategori cukup.

Selanjutnya untuk mengetahui presentasi kategori setiap komponen fisik dari sampel yang berjumlah 20 pemain, akan diperlihatkan pada tabel 2. Pada tabel 2 memperlihatkan pada komponen kekuatan otot (push up) 4 pemain (16,2\%) berkategori sempurna, 6 orang pemain $(27,3 \%)$ berkategori baik sekali, dan 10 pemain (56,5\%) berkategori cukup. Pada komponen kekuatan otot (sit up) dari 20 pemain futsal Saba Fast di Kabupaten Bandung Barat sebanyak 16 pemain $(83,8 \%)$ berkategori sempurna dan 4 pemain $(16,2 \%)$ berkategori baik. Pada komponen kelincahan dari 20 pemain futsal Saba Fast di Kabupaten Bandung Barat sebanyak (100\%) berkategori sempurna. Pada komponen kecepatan dari 20 pemain futsal Saba Fast di Kabupaten Bandung Barat sebanyak 18 pemain (90,9\%) kategori sempurna, 2 pemain $(9,1 \%)$ berkategori baik sekali. Pada komponen power otot tungkai dari 20 pemain futsal Saba Fast di Kabupaten Bandung Barat sebanyak 9 pemain (45,8\%) berkategori baik, dan 11 pemain $(54,2 \%)$ berkategori cukup. Pada kategori daya tahan dari 20 pemain futsal Saba Fast di Kabupaten Bandung Barat sebanyak 3 pemain $(12,4 \%)$ berkategori sempurna, 5 pemain $(23,5 \%)$ berkategori baik, 3 pemain $(12,4 \%)$ berkategori baik sekali dan 9 pemain $(51,7 \%)$ berkategori cukup.

Tabel 2. Presentasi Kategori Dari Setiap Komponen Fisik

\begin{tabular}{|l|c|c|c|c|c|c|}
\hline \multirow{2}{*}{ Komponen Fisik } & \multicolumn{7}{|c|}{ Presentasi Kategori } \\
\cline { 2 - 7 } & Sempurna & $\begin{array}{c}\text { Baik } \\
\text { Sekali }\end{array}$ & Baik & Cukup & Kurang & $\begin{array}{c}\text { Kurang } \\
\text { Sekali }\end{array}$ \\
\hline Kekuatan otot & $16,2 \%$ & $27,3 \%$ & - & $56,5 \%$ & - & - \\
\hline Kekuatan otot & $83,8 \%$ & - & $16,2 \%$ & - & - & - \\
\hline Kelincahan & $100 \%$ & - & - & - & - & - \\
\hline Kecepatan & $90,9 \%$ & $9,1 \%$ & - & - & - & - \\
\hline Power tungkai & - & - & $45,8 \%$ & $54,2 \%$ & - & - \\
\hline Daya tahan & $12,4 \%$ & $12,4 \%$ & $23,5 \%$ & $51,7 \%$ & - & - \\
\hline
\end{tabular}

\section{Komponen kekuatan otot (push up)}

Terlihat perolehan rata-rata presentasi tes kekuatan otot (push up) berkategori cukup yaitu sebesar $(56,5 \%)$. Dengan kekuatan otot seorang pemain futsal dapat mengatur sudut elevasi dari ketahanan saat menahan badan lawan. 


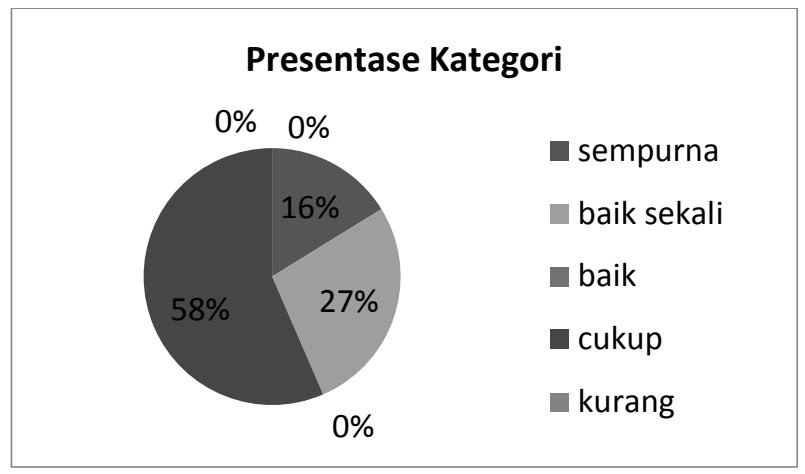

\section{Gambar 1. Presentase Kategori Tes Kekuatan Otot (Push Up)}

\section{Komponen kekuatan otot ( sit up)}

Terlihat perolehan rata-rata presentasi tes kekuatan otot (sit up) berkategori sempurna yaitu sebesar (83,8\%). Sebagai gambaran, pada saat bermain bola, otot hamstring dan quadriceps diperlukan secara intensif untuk gerakan mengandalkan tenaga, baik pada saat berlari maupun menendang. Artinya pada saat berlatih sepakbola, kedua otot ini digunakan untuk sprint, menendang, menumpu, dan memberi tenaga kepada kaki.

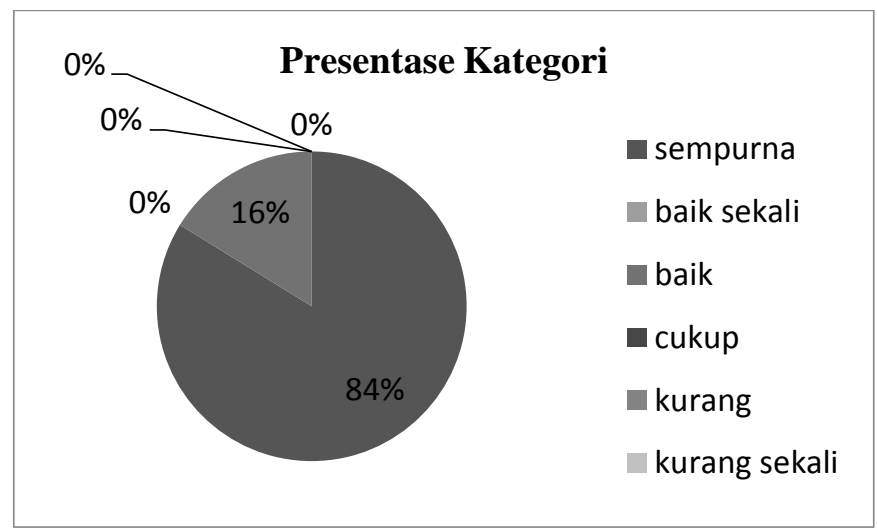

\section{Gambar 2. Presentase Kategori Tes Kekuatan Otot (Sit Up)}

\section{Komponen kelincahan}

Terlihat perolehan rata-rata presentasi tes kelincahan berkategori sempurna yaitu sebesar (100\%). Hal ini menunjukan bahwa kemampuan kelincahan menjadi sebuah kajian dalam penyusunan program latihan, sehingga komponen fisik kelincahan dari setiap pemain akan meningkat. Pemain akan lebih cepat dalam perubahan arah, karena dalam futsal situasi dan kondisi terus berubah-ubah selama 40 menit, baik itu adanya gangguan lawan, kondisi lapangan dan lainlain. 


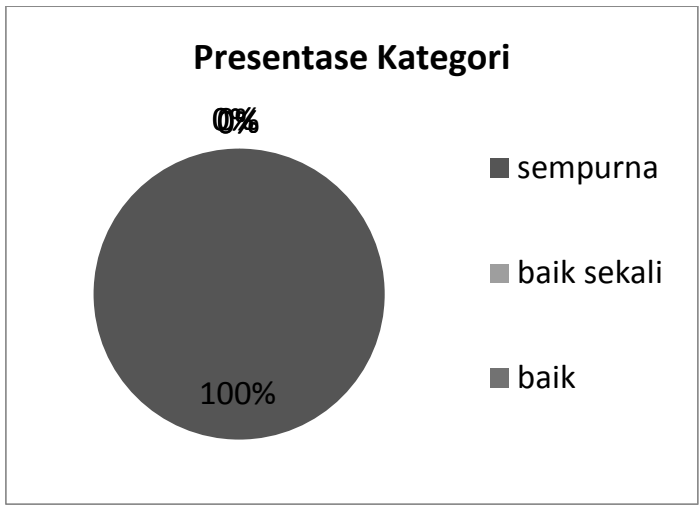

\section{Gambar 3. Presentase Kategori Tes Kelincahan}

\section{Komponen kecepatan}

Terlihat perolehan rata-rata presentasi tes kecepatan berkategori sempurna yaitu sebesar (90,9\%). Hal ini menunjukan bahwa salah satu kualitas kecepatan yang dimiliki pemain sangat baik karena komponen kecepatan sangat diperlukan dalam permainan futsal.

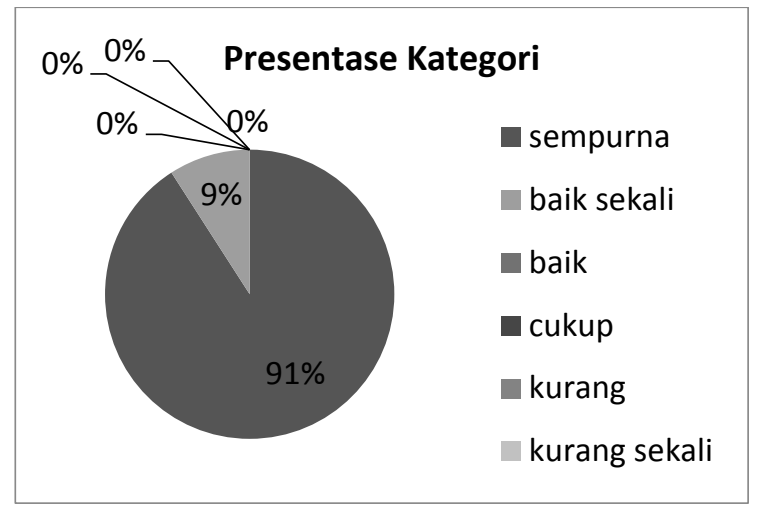

\section{Gambar 4. Presentase Kategori Tes Kecepatan}

\section{Komponen power otot tungkai}

Terlihat perolehan rata-rata presentasi tes power otot tungkai berkategori cukup yaitu sebesar $(54,2 \%)$. Hal ini menunjukan bahwa salah satu pola pelatihan fisik yang harus fokus untuk ditingkatkan yaitu komponen fisik power otot tungkai. Karena kekuatan otot tungkai ini digunakan saat berlari menggiring bola dan menendang bola, dengan power otot tungkai yang kuat maka kemampuan tendangan akan semakin kuat. 


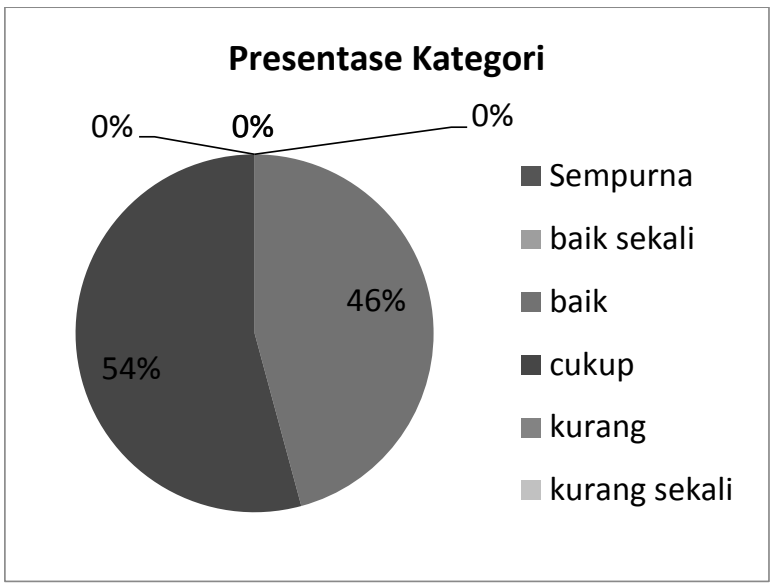

\section{Gambar 5. Presentase Kategori Tes Power Otot Tungkai}

\section{Kategori daya tahan}

Terlihat perolehan rata-rata presentasi tes daya tahan berkategori cukup yaitu sebesar $(51,7 \%)$. Daya tahan seorang pemain sangat diperlukan karena semakin pemain memiliki daya tahan baik akan semakin menunjang kemampuan dalam sebuah pertandingan. Dengan memperoleh kategori cukup, maka daya tahan yang dimiliki pemain perlu ditingkatkan dan dilatih secara terus menerus sehingga kapasitas daya tahan pemain akan meningkat dan target yang ditentukan akan tercapai secara maksimal.

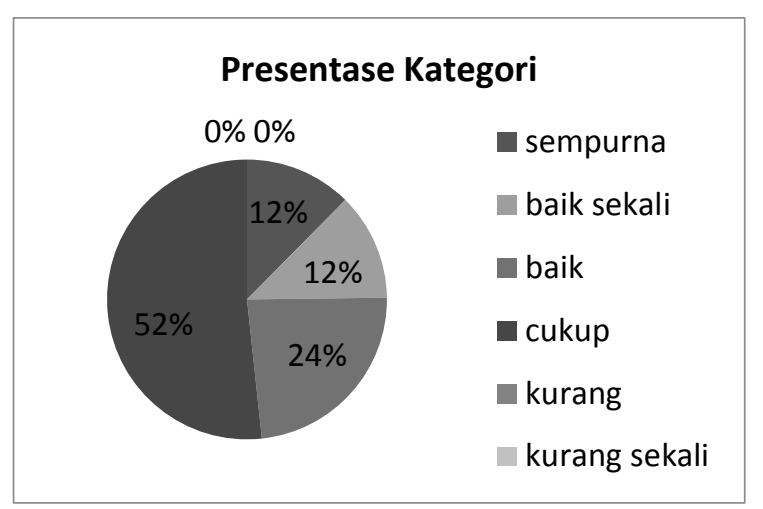

\section{Gambar 6. Presentase Kategori Tes Daya Tahan}

\section{Pembahasan}

Dari deskripsi hasil penelitian yang diperoleh bahwa profil kondisi fisik Pada komponen kekuatan otot (push up) 4 pemain $(16,2 \%)$ berkategori sempurna, 6 orang pemain $(27,3 \%)$ berkategori baik sekali, dan 10 pemain $(56,5 \%)$ berkategori cukup. Pada komponen kekuatan otot (sit up) dari 20 pemain futsal Saba Fast di Kabupaten Bandung Barat sebanyak 16 pemain (83,8\%) berkategori sempurna dan 4 pemain $(16,2 \%)$ berkategori baik. Pada komponen kelincahan dari 20 pemain futsal Saba Fast di Kabupaten Bandung Barat sebanyak (100\%) berkategori sempurna. Pada 
komponen kecepatan dari 20 pemain futsal Saba Fast di Kabupaten Bandung Barat sebanyak 18 pemain $(90,9 \%)$ kategori sempurna, 2 pemain $(9,1 \%)$ berkategori baik sekali. Pada komponen power otot tungkai dari 20 pemain futsal Saba Fast di Kabupaten Bandung Barat sebanyak 9 pemain $(45,8 \%)$ berkategori baik, dan 11 pemain $(54,2 \%)$ berkategori cukup. Pada kategori daya tahan dari 20 pemain futsal Saba Fast di Kabupaten Bandung Barat sebanyak 3 pemain $(12,4 \%)$ berkategori sempurna, 5 pemain $(23,5 \%)$ berkategori baik, 3 pemain $(12,4 \%)$ berkategori baik sekali dan 9 pemain $(51,7 \%)$ berkategori cukup.

Berdasarkan hasil penelitian tersebut menunjukan bahwa kondisi fisik pemain futsal Saba Fast di Kabupaten Bandung Barat dalam kategori baik. Keadaan fisik menjadi gambaran seberapa besar latihan yang sudah diberikan pelatih yang diterapkan kepada para pemainnya. Pemain futsal Saba Fast di Kabupaten Bandung Barat perlu meningkatkan kemampuan dan kondisi fisiknya secara maksimal melalui latihan dalam tim maupun latihan tambahan diluar tim. Dengan besarnya peran kondisi fisik bagi seorang pemain futsal menuntut tim futsal Saba Fast di Kabupaten Bandung Barat untuk dapat memiliki kondisi fisik yang maksimal. Selain itu tuntutan bahwa tim futsal Saba Fast di Kabupaten Bandung Barat merupakan salah satu tim yang berkompetisi di ASKAB (Asosiasi Kabupaten) Bandung Barat yang memiliki persaingan yang cukup ketat.

Secara khusus tuntutan pemain untuk dapat memiliki kondisi fisik yaitu untuk dapat mendukung kinerja pemain untuk dapat memiliki kondisi fisik yaitu untuk dapat menunjang kinerja pemain di dalam tim agar mampu bermain dengan maksimal. Permainan yang diharapkan sebuah penerapan hasil latihan harus mampu didukung oleh kondisi latihan yang baik. Pemain futsal Saba Fast di Kabupaten Bandung Barat akan mampu bermain dengan baik apabila memiliki mental, skill dan dukungan kondisi fisik yang prima maka peman akan mampu menerapkan hasil latihan secara maksimal.

\section{KESIMPULAN}

Berdasarkan hasil penelitian dan pembahasannya, maka dapat diambil suatu kesimpulan bahwa secara keseluruhan kemampuan kondisi fisik atlet futsal aba Fast yang dipersiapkan untuk pertandingan Liga Futsal Kabupaten Bandung Barat berada dalam kategori baik, dengan rincian sebagai berikut:

- Komponen kekuatan otot (push up) (56,5\%) berkategori cukup.

- Pada komponen kekuatan otot (sit up) $(83,8 \%)$ berkategori sempurna.

- Pada komponen kelincahan (100\%) berkategori sempurna.

- Pada komponen kecepatan (90,9\%) kategori sempurna. 
- Pada komponen power otot tungkai $(54,2 \%)$ berkategori cukup.

- Pada kategori daya tahan $(51,7 \%)$ berkategori cukup.

Dengan perolehan rata-rata persentase dari keseluruhan komponen kondisi fisik yaitu pemain futsal Saba Fast di Kabupaten Bandung Barat. Hasil rata-rata tes kekuatan otot (push up) yaitu 42.65 berkategori sempurna, tes kekuatan otot (sit up) yaitu 44.60 berkategori sempurna, kelincahan perolehan rata-rata tes 17.60 detik dengan kategori cukup, hasil rata-rata tes kecepatan perolehan rata-rata tes 3.86 detik dengan kategori baik, kekuatan otot tungkai yaitu 1.06 berkategori sempurna, tes daya tahan perolehan rata-rata tes 16.2 dengan kategori cukup.

\section{DAFTAR PUSTAKA}

Almahdi, Zaidan. (2008). Bisnis Futsal. Yogyakarta : Ayyana Mangunegaraan.

Arikunto, Suharsmi. (2012). Prosedur Penelitian. Suatu Pendekatan Praktek. Jakarta: PT. Rineka Cipta.

Lhaksana, Justinus. (2011). Taktik \& Strategi Futsal Modern. Jakarta: Be Champion, Penebar Swadaya Group.

Notoatmodjo, Soekidjo. (2012). Metodologi Penelitian Kesehatan. Edisi revisi. Jakarta: PT. Rineka Cipta.

Rudiyanto. (2012). Hubungan Berat Badan Tinggi Badan dan Panjang Tungkai dengan Kelincahan. Journal of Sport Sciences and Fitnes 1(2). (2012).

Setiawan, Iwan.,et al. (2005). Manusia dan Olahraga. Bandung : ITB.

Sugiyono. (2014). Metode Penelitian Bisnis (Pendekatan Kuantitatif, Kualitatif, dan R\&D. Bandung: Alfabeta.

Surya. (2013). Daya Tahan Timnas Futsal Putri Harus Diperbaiki. (http://suryaonline.co/futsalic/daya-tahan-timnas-futsal-putri-harusdiperbaiki/, diakses 15 Juni 2016, pukul 14.15 WIB. 